\title{
Noninvasive Imaging of Drug-Induced Liver Injury with 18F-DFA PET
}

\author{
Jessica R. Salas ${ }^{1,2}$, Bao Ying Chen ${ }^{1,2}$, Alicia Wong ${ }^{1,2}$, Sergio Duarte ${ }^{3}$, Stephanie A.K. Angarita ${ }^{3}$, \\ Gerald S. Lipshutz ${ }^{1,4,5}$, Owen N. Witte ${ }^{1,4,6}$, and Peter M. Clark ${ }^{1,2,4}$ \\ ${ }^{1}$ Department of Molecular and Medical Pharmacology, University of California, Los Angeles California; ${ }^{2}$ Crump Institute for \\ Molecular Imaging, University of California, Los Angeles California; ${ }^{3}$ Department of Surgery, University of California, Los Angeles \\ California; ${ }^{4}$ Eli and Edythe Broad Center of Regenerative Medicine and Stem Cell Research, University of California, Los Angeles \\ California; ${ }^{5}$ Intellectual and Developmental Disabilities Research Center, University of California, Los Angeles California; and \\ ${ }^{6}$ Department of Microbiology, Immunology and Molecular Genetics, University of California, Los Angeles California
}

\begin{abstract}
Drug-induced liver failure is a significant indication for a liver transplant, and unexpected liver toxicity is a major reason that otherwise effective therapies are removed from the market. Various methods exist for monitoring liver injury but are often inadequate to predict liver failure. New diagnostic tools are needed. Methods: We evaluate in a preclinical model whether ${ }^{18} \mathrm{~F}$-2-deoxy-2-fluoroarabinose $\left({ }^{18} \mathrm{~F}-\mathrm{DFA}\right)$, a PET radiotracer that measures the ribose salvage pathway, can be used to monitor acetaminophen-induced liver injury and failure. Mice treated with vehicle, 100,300 , or $500 \mathrm{mg} / \mathrm{kg}$ acetaminophen for 7 or $21 \mathrm{~h}$ were imaged with ${ }^{18} \mathrm{~F}-\mathrm{FDG}$ and ${ }^{18} \mathrm{~F}$-DFA PET. Hepatic radiotracer accumulation was correlated to survival and percentage of nonnecrotic tissue in the liver. Mice treated with acetaminophen and vehicle or $\mathrm{N}$-acetylcysteine were imaged with ${ }^{18} \mathrm{~F}$-DFA PET. ${ }^{18} \mathrm{~F}-\mathrm{DFA}$ accumulation was evaluated in human hepatocytes engrafted into the mouse liver. Results: We show that hepatic ${ }^{18} \mathrm{~F}-$ DFA accumulation is $49 \%-52 \%$ lower in mice treated with high-dose acetaminophen than in mice treated with low-dose acetaminophen or vehicle. Under these same conditions, hepatic ${ }^{18} \mathrm{~F}-\mathrm{FDG}$ accumulation was unaffected. At $21 \mathrm{~h}$ after acetaminophen treatment, hepatic ${ }^{18} \mathrm{~F}$ DFA accumulation can distinguish mice that will succumb to the liver injury from those that will survive it (6.2 vs. 9.7 signal to background, respectively). Hepatic ${ }^{18} \mathrm{~F}$-DFA accumulation in this model provides a tomographic representation of hepatocyte density in the liver, with a $R^{2}$ between hepatic ${ }^{18} \mathrm{~F}$-DFA accumulation and percentage of nonnecrotic tissue of 0.70 . PET imaging with ${ }^{18} \mathrm{~F}$-DFA can be used to distinguish effective from ineffective resolution of acetaminopheninduced liver injury with $N$-acetylcysteine (15.6 vs. 6.2 signal to background, respectively). Human hepatocytes, in culture or engrafted into a mouse liver, have levels of ribose salvage activity similar to those of mouse hepatocytes. Conclusion: Our findings suggest that PET imaging with ${ }^{18} \mathrm{~F}-\mathrm{DFA}$ can be used to visualize and quantify druginduced acute liver injury and may provide information on the progression from liver injury to hepatic failure.
\end{abstract}

Key Words: PET imaging; drug-induced liver failure; hepatocytes

J Nucl Med 2018; 59:1308-1315

DOI: 10.2967/jnumed.117.206961

Received Dec. 14, 2017; revision accepted Feb. 21, 2018.

For correspondence or reprints contact: Peter M. Clark, Crump Institute,

Box 951770, 4333 CNSI, Los Angeles, CA 90095-1770.

E-mail: pclark@mednet.ucla.edu

Guest Editor: Carolyn J. Anderson, University of Pittsburgh

Published online Mar. 1, 2018.

COPYRIGHT (C 2018 by the Society of Nuclear Medicine and Molecular Imaging.
D rug-induced liver injury can be provoked by a variety of agents including tyrosine kinase inhibitors (pazopanib), antibodydrug conjugates (trastuzumab emtansine), and analgesics (acetaminophen) (1-3); is a frequent indication for a liver transplant; and is a major reason for postmarket drug warnings and withdrawal (4-6). Various methods exist for assessing liver health during drug-induced liver injury. These include static measurements of liver-selective enzymes and metabolites, such as aspartate transaminase (AST), alanine transaminase (ALT), and bilirubin; liver biopsies; and imaging with CT, MRI, and ultrasound (1,4,5,7-12). All of these methods have proven clinical value but do not provide a complete picture of liver health. In particular, specifically identifying patients who will progress from acute liver injury to fulminant liver failure remains a clinical challenge $(1,6,13,14)$. Tomographic molecular imaging of select liver functions could provide additional information not captured with these other methods.

Recently we developed 2 PET tracers, ${ }^{18} \mathrm{~F}$-2-deoxy-2-fluoroarabinose $\left({ }^{18} \mathrm{~F}-\mathrm{DFA}\right)$ and ${ }^{18} \mathrm{~F}$-2-deoxy-2-fluororibose ( ${ }^{18} \mathrm{~F}$-2-DFR), to measure ribose salvage activity $(15,16)$. The ribose salvage pathway is most active in the liver, leading to significant and specific accumulation of ${ }^{18} \mathrm{~F}-\mathrm{DFA},{ }^{18} \mathrm{~F}-2-\mathrm{DFR}$, and their metabolites in this organ $(15,16)$. Previously we showed that hepatic ${ }^{18} \mathrm{~F}-\mathrm{DFA}$ and ${ }^{18} \mathrm{~F}-2$-DFR accumulation are lower in mouse models of fatty liver disease and, in a limited study, in mice treated with 1 dose of acetaminophen (300 $\mathrm{mg} / \mathrm{kg}$ ) at one specific time point $(24 \mathrm{~h}$ after injection) $(15,16)$. However various questions remain on a potential role for ${ }^{18} \mathrm{~F}$-DFA in imaging liver injury and failure.

We hypothesized that ${ }^{18} \mathrm{~F}$-DFA PET imaging could be used to noninvasively monitor and study acetaminophen-induced liver injury and failure. Though we previously showed that ${ }^{18} \mathrm{~F}-2$-DFR was subject to less defluorination than ${ }^{18} \mathrm{~F}$-DFA (16), ${ }^{18} \mathrm{~F}$-DFA was chosen to be studied here because of the commercial availability of the synthetic precursor and the fact that ${ }^{18} \mathrm{~F}$-DFA could be prepared on an automated radiosynthesizer (17). Our results suggest that PET imaging with a radiotracer that measures ribose salvage activity can be used to monitor acute liver failure and may provide information not available with current diagnostic methods.

\section{MATERIALS AND METHODS}

Mice

C57BL/6 male mice (10-11 wk old) were used for all experiments unless otherwise noted. Immunodeficient male mice lacking the enzyme fumarylacetoacetate hydrolase $\left(\mathrm{Fah}^{-1-} / \mathrm{Rag}^{-1-} / \mathrm{Il} 2 \mathrm{rg}^{-/-}\right.$or 
FRG mice, 12 wk old; Yecuris) were maintained on drinking water supplemented with 2-(2-nitro-4-trifluoromethylbenzoyl)-1,3-cyclohexanedione (NTBC, $16 \mathrm{mg} / \mathrm{L}$; Yecuris) and then switched to drinking water without NTBC. All animal experiments were approved by the UCLA Animal Research Committee.

\section{Drug Treatments}

For the acetaminophen group, mice, fasted overnight, were injected intraperitoneally with vehicle or acetaminophen $(15 \mathrm{mg} / \mathrm{mL}$ in $0.9 \%$ w/v saline). For the $N$-acetylcysteine (NAC) group, mice were injected intraperitoneally with vehicle or NAC $(1200 \mathrm{mg} / \mathrm{kg}), 1$ or $4 \mathrm{~h}$ after acetaminophen treatments.

\section{Serum AST, ALT, and Bilirubin Levels}

ALT and AST Liquid Reagent Set (Pointe Scientific) and Bilirubin Assay (Sigma-Aldrich) kits were used following the manufacturer's protocol except that all the reagents and samples were scaled down 10-fold.

\section{Histologic Analysis}

The right liver lobe was removed, washed in $1 \mathrm{X}$ phosphate-buffered saline, and fixed (10\% formalin, $1 \mathrm{~d}$ ). Sections were stained for hematoxylin and eosin (H\&E) or with an antibody against fumarylacetoacetate hydrolase (FAH) (Yecuris 20-0034; 1:1,000; room temperature, $1 \mathrm{~h}$ ). Percentage of FAH-expressing hepatocytes and nonnecrotic tissue was quantified with Ilastik (version 1.2.0) and ImageJ (version 1.51n) $(18,19)$.

\section{PET Tracers}

${ }^{18} \mathrm{~F}$-DFA was synthesized as previously described (17). ${ }^{18} \mathrm{~F}-\mathrm{FDG}$ was obtained from the UCLA Translational Imaging Division.

\section{PET/CT Imaging}

Mice were injected with ExiTron nano 12,000 (100 $\mu \mathrm{L}), 3 \mathrm{~d}$ before the PET imaging experiment. Mice were anesthetized, injected with approximately $2.96 \mathrm{MBq}$ of ${ }^{18} \mathrm{~F}-\mathrm{FDG}$ (after an overnight fast) or ${ }^{18} \mathrm{~F}$ DFA, and after $60 \mathrm{~min}$ imaged for $10 \mathrm{~min}$ on a G8 PET/CT (SOFIE Biosciences). Different cohorts of mice were used for the 7- and 21-h postacetaminophen treatment ${ }^{18} \mathrm{~F}$-DFA imaging experiments.

\section{PET Quantification}

An observer unaware of the treatment groups performed the PET quantification using only the $\mathrm{CT}$ image to place the regions of interest. ${ }^{18} \mathrm{~F}$-DFA and ${ }^{18} \mathrm{~F}$-FDG accumulation were normalized to their respective accumulation in the brain and right forelimb triceps. Brain was used as a reference region for the quantification of ${ }^{18} \mathrm{~F}$-DFA accumulation as we have never identified specific accumulation of ${ }^{18} \mathrm{~F}$-DFA in the brain, and the same brain region could be readily identified and quantified across different mice. Image-derived blood ${ }^{18} \mathrm{~F}-\mathrm{DFA}$ levels were quantified from the left ventricle. Hepatic ${ }^{18} \mathrm{~F}-\mathrm{DFA}$ contrast, correlation, and entropy were determined using the GLCM Texture plugin in ImageJ (version 1.50i) (19).

\section{Autoradiography}

Autoradiography was performed as previously described (20).

\section{${ }^{3} \mathrm{H}-$ Ribose Accumulation}

Mouse hepatocytes were isolated as previously described (15). Human hepatocytes (Corning Inc; lot \#373) were plated following the manufacturer's protocol. ${ }^{3} \mathrm{H}$-ribose accumulation experiments were performed as previously described (15).

\section{Human Hepatocyte Engraftment into FRG Mice}

FRG mice were inoculated with CuRx uPA Liver Tx Enhancer $\left(1.25 \times 10^{9} \mathrm{pfu} / 25 \mathrm{~g}\right.$; Yecuris). The next day, fresh human hepatocytes $\left(1 \times 10^{6}\right.$; Yecuris) were prepared according to the distributor's protocol and injected into the spleen. For the next 3 mo, mice were cycled on and off NTBC. For the final $3 \mathrm{mo}$, mice were only provided drinking water without NTBC.

\section{Mouse Numbers}

The following are mouse numbers in the experimental groups: (1) $7 \mathrm{~h}$ acetaminophen treatment, imaged with ${ }^{18} \mathrm{~F}-\mathrm{DFA}$ and analyzed for blood chemistries-all doses: $n=4$; survived: $n=2$; did not survive: $n=6$; (2) $21 \mathrm{~h}$ acetaminophen treatment, imaged with ${ }^{18} \mathrm{~F}-\mathrm{DFA}$ and analyzed for blood chemistries-vehicle and $100 \mathrm{mg} / \mathrm{kg}: n=4 ; 300$ mg/kg: $n=10 ; 500 \mathrm{mg} / \mathrm{kg}: n=3$; survived: $n=5$; did not survive: $n=8$; (3) autoradiography experiments: $n=2$; (4) hepatic ${ }^{18} \mathrm{~F}-\mathrm{DFA}$ accumulation and nonnecrotic tissue correlation study: $n=7$; (5) vehicle or acetaminophen-treated mice treated with NAC - vehicle: $n=3$; acetaminophen + NAC $(1 \mathrm{~h}): n=3$; acetaminophen + NAC (4 h): $n=2$; (6) human hepatocyte experiments-control FRG mice: $n=2$; human hepatocyte-engrafted FRG mice: $n=2$; (7) KaplanMeier curve—vehicle: $n=8 ; 100 \mathrm{mg} / \mathrm{kg}: n=8 ; 300 \mathrm{mg} / \mathrm{kg}: n=14$; $500 \mathrm{mg} / \mathrm{kg}: n=10$; (8) serum AST and ALT values $-7 \mathrm{~h}$, all doses: $n=6 ; 21 \mathrm{~h}$, vehicle: $n=4 ; 100$ and $300 \mathrm{mg} / \mathrm{kg}: n=6 ; 500 \mathrm{mg} / \mathrm{kg}$ : $n=5$; (9) histology: $n=2$; (10) acetaminophen-treated mice imaged with ${ }^{18} \mathrm{~F}-\mathrm{FDG}$ and analyzed for blood chemistries-vehicle and $7 \mathrm{~h}$ : $n=3$; 21 h: $n=4$; (11) FRG mouse liver injury experiments: $n=6$, imaged before and after withdrawal of NTBC.

\section{Statistics}

Data are plotted as mean \pm SE of the mean (SEM). Experimentspecific statistical tests are described in their respective figure legends. All analyses were performed using GraphPad Prism (version 7.01; GraphPad Software).

\section{RESULTS}

\section{Mouse Model of Drug-Induced Liver Injury}

Mice provide a model system in which to study drug-induced liver injury (21-23). Consistent with published results, we found that mice succumb to acetaminophen-induced liver injury in a dose-dependent manner. All of the mice treated with $100 \mathrm{mg} / \mathrm{kg}$ acetaminophen survived, but only about $50 \%$ and $10 \%$ of the mice treated with 300 and $500 \mathrm{mg} / \mathrm{kg}$ acetaminophen, respectively, survived (Supplemental Fig. 1A; supplemental materials are available at http://jnm.snmjournals.org). The earliest time point at which maximum ALT levels occur in mice is $7 \mathrm{~h}$ after acetaminophen treatment $(24,25)$, and mice treated with $500 \mathrm{mg} / \mathrm{kg}$ acetaminophen succumb to liver failure starting at $24 \mathrm{~h}$ posttreatment (Supplemental Fig. 1A). Therefore, we chose to study mice at 7 and $21 \mathrm{~h}$ after acetaminophen treatment. Mice treated with high-dose (300 and $500 \mathrm{mg} / \mathrm{kg}$ ) acetaminophen for 7 and $21 \mathrm{~h}$ had elevated serum ALT and AST levels, and liver sections from these mice displayed significant necrosis in zone 3 hepatocytes by $H \& E$ staining (Supplemental Figs. 1B-1D). These studies validate our mouse model and provide us with a system in which to test our hypothesis.

\section{PET Imaging with ${ }^{18}$ F-FDG Cannot Distinguish Vehicle-Treated from High-Dose $(500 \mathrm{mg} / \mathrm{kg}$ ) Acetaminophen-Treated Mice}

${ }^{18}$ F-FDG is the most widely used PET tracer although its potential utility in studying liver disease is complicated by the hormonal regulation of liver glucose consumption (26-28). We first tested the utility of ${ }^{18}$ F-FDG imaging for studying druginduced liver injury. Serum AST and ALT levels were elevated, but hepatic ${ }^{18} \mathrm{~F}-\mathrm{FDG}$ accumulation was unaffected $(P=0.56)$ in mice 7 and $21 \mathrm{~h}$ after treatment with $500 \mathrm{mg} / \mathrm{kg}$ acetaminophen (Supplemental Figs. 2A-2C). This suggests that PET imaging with ${ }^{18}$ F-FDG will be unable to provide information on acetaminopheninduced liver injury. 
PET Imaging with ${ }^{18}$ F-DFA 7 Hours After Acetaminophen Treatment Can Distinguish Low- (100 mg/kg) and High- (300 and $500 \mathrm{mg} / \mathrm{kg}$ ) Dose Acetaminophen-Treated Mice

The radiotracer ${ }^{18} \mathrm{~F}$-DFA accumulates strongly in liver hepatocytes through ribose salvage activity (15), and its accumulation could be affected by acetaminophen. High-dose (300 and $500 \mathrm{mg} / \mathrm{kg}$ ) acetaminophen treatment caused a significant $52 \%$ decrease in hepatic ${ }^{18} \mathrm{~F}$-DFA accumulation compared with low-dose $(100 \mathrm{mg} / \mathrm{kg})$ acetaminophen and vehicle treatment $(P<0.0001$; Figs. 1A and 1B). ${ }^{18}$ F-DFA accumulation in the mice treated with high-dose (300 and $500 \mathrm{mg} / \mathrm{kg}$ ) acetaminophen was significantly higher in the kidneys and intestines $(P<0.0001$ and 0.001 , respectively) but similar in other organs including the lungs and heart than in vehicle-treated mice (Supplemental Fig. 3A), potentially suggesting increased renal excretion and intestinal accumulation of the radiotracer in the absence of specific hepatic accumulation. These results were independent of whether organ-specific ${ }^{18} \mathrm{~F}$-DFA accumulation was normalized to brain ${ }^{18} \mathrm{~F}$-DFA accumulation or image-derived blood ${ }^{18}$ F-DFA levels (Supplemental Fig. 3B). The decrease in hepatic ${ }^{18} \mathrm{~F}$-DFA accumulation was similar in mice treated with either 300 or $500 \mathrm{mg} / \mathrm{kg}$ acetaminophen $(P=0.05)$ and was indistinguishable between the high-dose (300 and $500 \mathrm{mg} / \mathrm{kg}$ ) acetaminophentreated mice that would survive the injury and those that would not $(P=0.50$; Figs. 1A and 1C). As expected (1), ALT, AST, and total bilirubin levels also failed to discriminate between mice that survived high-dose (300 and $500 \mathrm{mg} / \mathrm{kg}$ ) acetaminophen from those that did $\operatorname{not}(P=0.56,0.70$, and 0.98 , respectively; Fig. 1D). Visually all the mice looked equally sick.

These results could be broadly applicable across various types of acute liver injury or could be specific to acetaminophen toxicity. FRG mice undergo liver failure in the absence of the drug NTBC due to buildup of the hepatotoxic tyrosine catabolite fumarylacetoacetate (29). FRG mice withdrawn from NTBC for 2 wk displayed histologic evidence of hepatocyte damage, compared with mice maintained on NTBC, and succumb to liver failure within approximately $2.5 \mathrm{wk}$ (Supplemental Figs. 4A and 4B). The amount of hepatocellular damage in this model is considerably less than in the acetaminophen model. Hepatic ${ }^{18} \mathrm{~F}-\mathrm{DFA}$ accumulation was 23\% lower in FRG mice withdrawn from the NTBC for 2 wk than hepatic ${ }^{18} \mathrm{~F}$-DFA accumulation in these mice immediately before withdrawing the NTBC $(P=0.007$; Supplemental Figs. $4 \mathrm{C}$ and $4 \mathrm{D}$ ), suggesting that ${ }^{18} \mathrm{~F}$-DFA PET could image liver injury and failure caused by multiple different sources.

PET Imaging with ${ }^{18}$ F-DFA 21 Hours After Acetaminophen Treatment Can Distinguish Mice That Will Survive High-Dose ( 300 and $500 \mathrm{mg} / \mathrm{kg}$ ) Acetaminophen from Mice That Will Not

At $21 \mathrm{~h}$ after acetaminophen treatment, mice treated with highdose (300 and $500 \mathrm{mg} / \mathrm{kg}$ ) acetaminophen had $49 \%$ lower hepatic ${ }^{18} \mathrm{~F}-\mathrm{DFA}$ accumulation than mice treated with vehicle and $100 \mathrm{mg} / \mathrm{kg}$

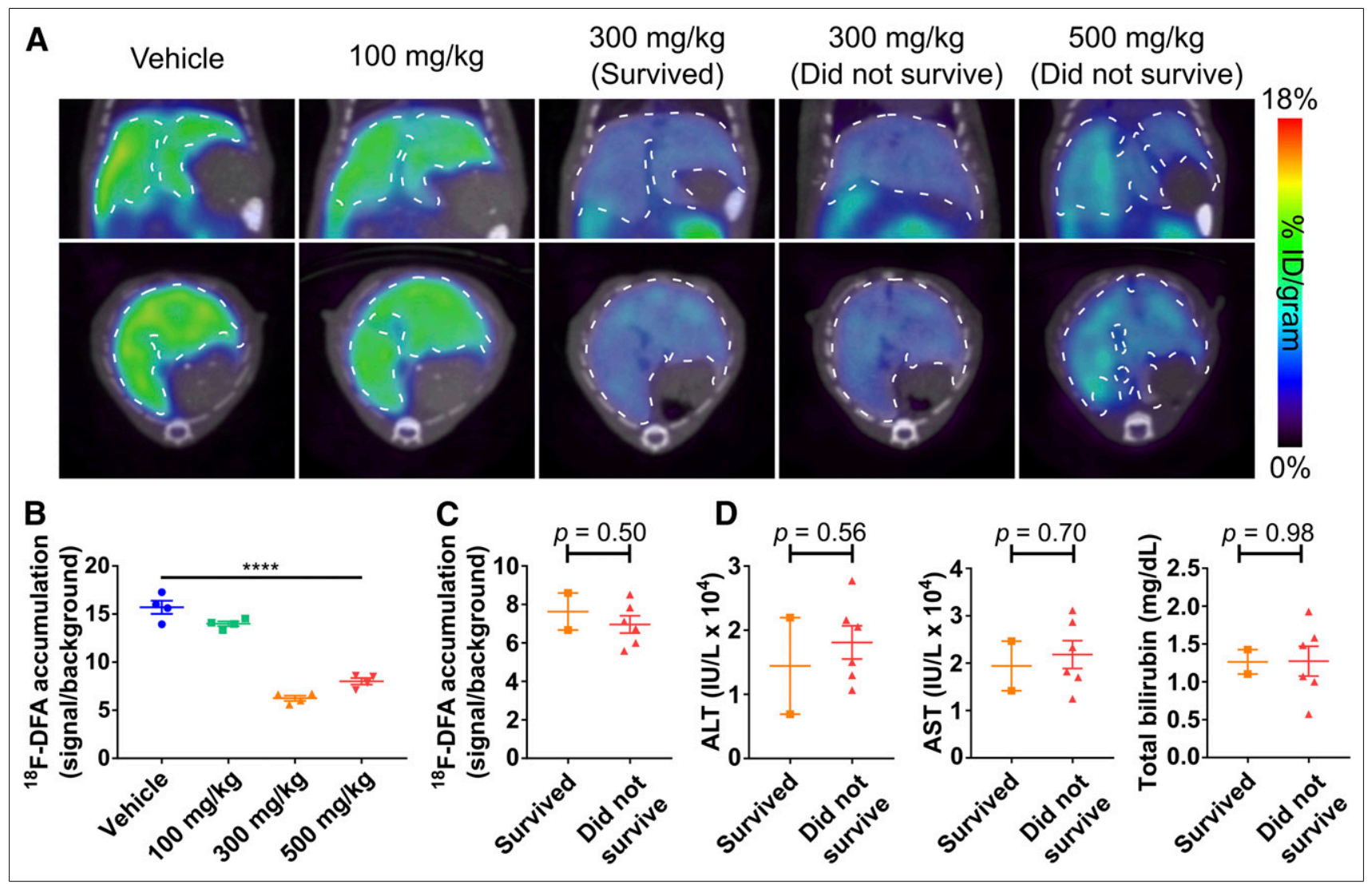

FIGURE 1. PET imaging with ${ }^{18} \mathrm{~F}-\mathrm{DFA} 7 \mathrm{~h}$ after acetaminophen treatment can distinguish low- and high-dose acetaminophen-treated mice but cannot distinguish mice that will survive high-dose acetaminophen from those that will not. (A) Representative transverse and coronal ${ }^{18} \mathrm{~F}-\mathrm{DFA}$ $\mathrm{PET} / \mathrm{CT}$ images of mice, $7 \mathrm{~h}$ after treatment with saline vehicle or acetaminophen. Dotted white lines encircle livers. Quantification of hepatic ${ }^{18} \mathrm{~F}-\mathrm{DFA}$ accumulation in mice, $7 \mathrm{~h}$ after treatment with saline vehicle or acetaminophen, plotted by acetaminophen dose (B) or survival status (C). (D) ALT, AST, and total bilirubin levels from serum of mice treated for $7 \mathrm{~h}$ with high-dose acetaminophen, plotted by survival status. All doses: $n=4$; survived: $n=2$; did not survive: $n=6$. One-way ANOVA for B; unpaired $t$ tests for $\mathrm{C}$ and $\mathrm{D}$. ${ }^{\star \star \star \star} P<0.0001$. 
acetaminophen $(P<0.0001$; Figs. $2 \mathrm{~A}$ and $2 \mathrm{~B})$. Unlike the $7 \mathrm{~h}$ postacetaminophen treatment results, hepatic ${ }^{18} \mathrm{~F}$-DFA accumulation could clearly distinguish mice that would survive the high-dose (300 and $500 \mathrm{mg} / \mathrm{kg}$ ) acetaminophen treatment from those that would not $(P=0.0003$; Figs. $2 \mathrm{~A}$ and $2 \mathrm{C})$. Hepatic ${ }^{18} \mathrm{~F}-\mathrm{DFA}$ accumulation in mice treated with high-dose (300 and $500 \mathrm{mg} / \mathrm{kg}$ ) acetaminophen that survive was intermediate between ${ }^{18} \mathrm{~F}$-DFA accumulation in nonsurviving mice and in vehicle-treated mice (Figs. 2B and 2C). ALT, AST, and total bilirubin levels could not distinguish mice that survived the high-dose (300 and $500 \mathrm{mg} / \mathrm{kg}$ ) acetaminophen treatment from those that did not $(P=0.26,0.59$, and 0.73 , respectively; Fig. 2D), and all the mice looked equally sick.

PET images contain voxel-level values from which textural features, such as entropy, contrast, and variability, can be extracted (30-32). These additional features can be better predictors of radiochemotherapeutic responses in esophageal and non-small cell lung cancers and may suffer less variability than bulk values such as mean tracer accumulation $(30,31)$. Voxel-to-voxel hepatic correlation in ${ }^{18} \mathrm{~F}$-DFA accumulation was higher and voxel-tovoxel hepatic contrast and entropy in ${ }^{18} \mathrm{~F}-\mathrm{DFA}$ accumulation were lower in the mice that did not survive the high-dose (300 and $500 \mathrm{mg} / \mathrm{kg}$ ) acetaminophen treatment than in the mice that did ( $P=0.002,0.0004$, and 0.0006, respectively; Supplemental Figs. $5 \mathrm{~A}-5 \mathrm{C})$. This is consistent with an overall decrease in voxels with high ${ }^{18} \mathrm{~F}-\mathrm{DFA}$ accumulation across the liver in the nonsurviving cohort of mice but also suggests that the distribution of healthy hepatic tissue across the liver may be important for determining the physiologic effects of high-dose (300 and $500 \mathrm{mg} / \mathrm{kg}$ ) acetaminophen. Notably the coefficient of variation for the entropy measurements is lowest among all the measured values, suggesting that it may serve as the best quantity for studying drug-induced liver injury.

Combining the results from both time points provides a kinetic picture of the liver responding to high-dose (300 and $500 \mathrm{mg} / \mathrm{kg}$ ) acetaminophen in surviving and nonsurviving cohorts (Supplemental Fig. 6). Consistent with immunohistochemical and serum analyses, the data indicate that all mice, independent of survival, suffer significant and possibly equivalent liver damage within $7 \mathrm{~h}$ of high-dose (300 and $500 \mathrm{mg} / \mathrm{kg}$ ) acetaminophen treatment. Only mice that begin to recover hepatic ${ }^{18} \mathrm{~F}$-DFA accumulation within $21 \mathrm{~h}$ of the acetaminophen treatment will survive. Mice for which hepatic ${ }^{18} \mathrm{~F}-\mathrm{DFA}$ accumulation is unchanged from 7 to $21 \mathrm{~h}$ do not survive.

\section{${ }^{18}$ F-DFA PET Provides a Tomographic Representation of Hepatocyte Density in the Liver During Acetaminophen- Induced Liver Injury}

The livers of mice treated with high-dose (300 and $500 \mathrm{mg} / \mathrm{kg}$ ) acetaminophen undergo considerable necrosis (Supplemental Fig. 1D). ${ }^{18}$ F-DFA accumulation could correlate with the amount of

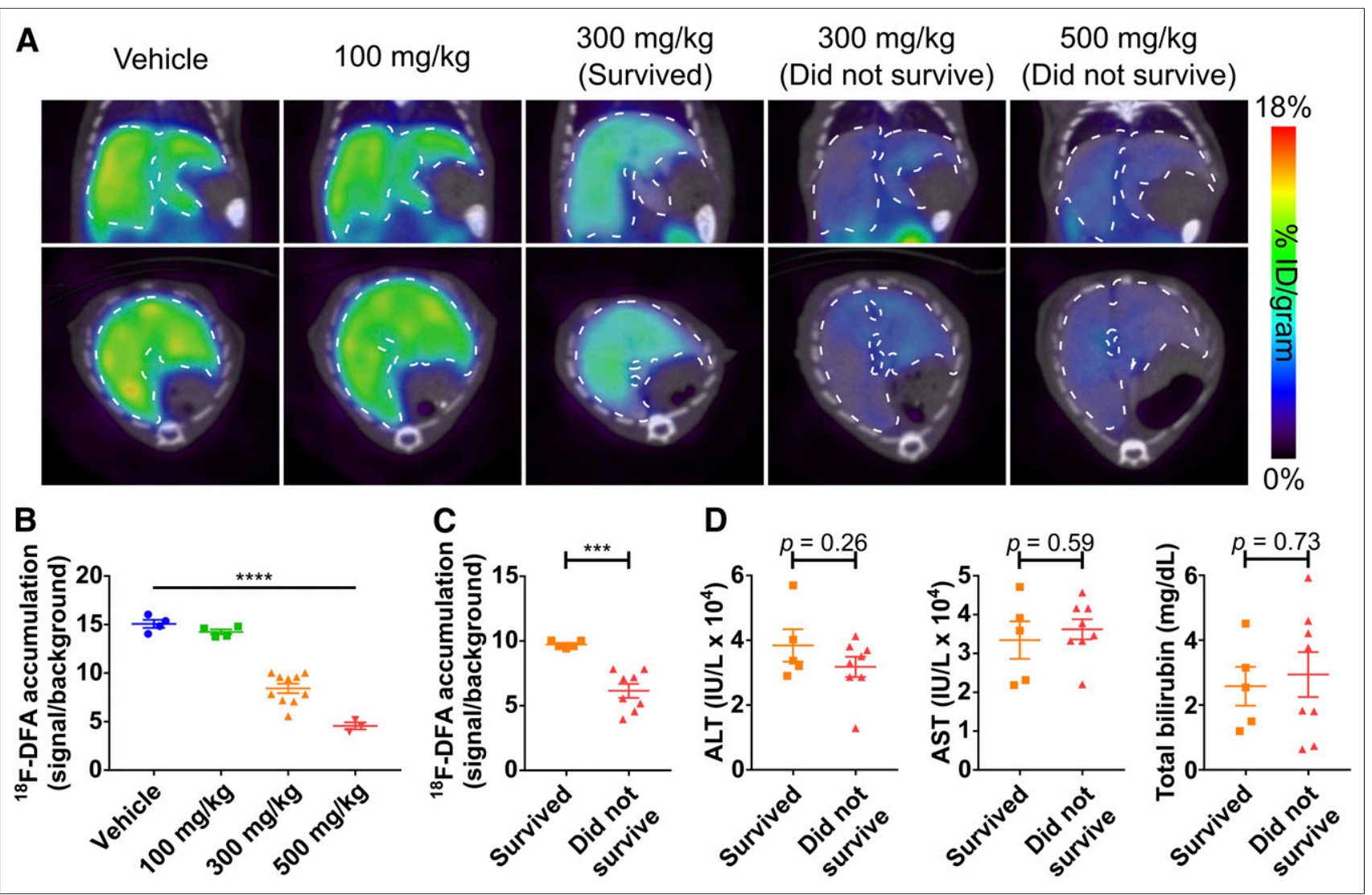

FIGURE 2. PET imaging with ${ }^{18} \mathrm{~F}-\mathrm{DFA} 21 \mathrm{~h}$ after acetaminophen treatment can distinguish mice that will survive high-dose acetaminophen from mice that will not. (A) Representative transverse and coronal ${ }^{18} \mathrm{~F}$-DFA PET/CT images of mice, $21 \mathrm{~h}$ after treatment with saline vehicle or acetaminophen. Quantification of hepatic ${ }^{18} \mathrm{~F}$-DFA accumulation in mice, $21 \mathrm{~h}$ after treatment with saline vehicle or acetaminophen, plotted by acetaminophen dose (B) or survival status (C). (D) ALT, AST, and total bilirubin levels from serum of mice treated with high-dose acetaminophen for $21 \mathrm{~h}$, plotted by survival status. Vehicle and $100 \mathrm{mg} / \mathrm{kg}: n=4 ; 300 \mathrm{mg} / \mathrm{kg}: n=10 ; 500 \mathrm{mg} / \mathrm{kg}: n=3$; survived: $n=5$; did not survive: $n=8$. One-way ANOVA for B; unpaired $t$ tests for $C$ and D. ${ }^{* \star \star} P<0.001 .{ }^{\star \star \star \star} P<0.0001$. 


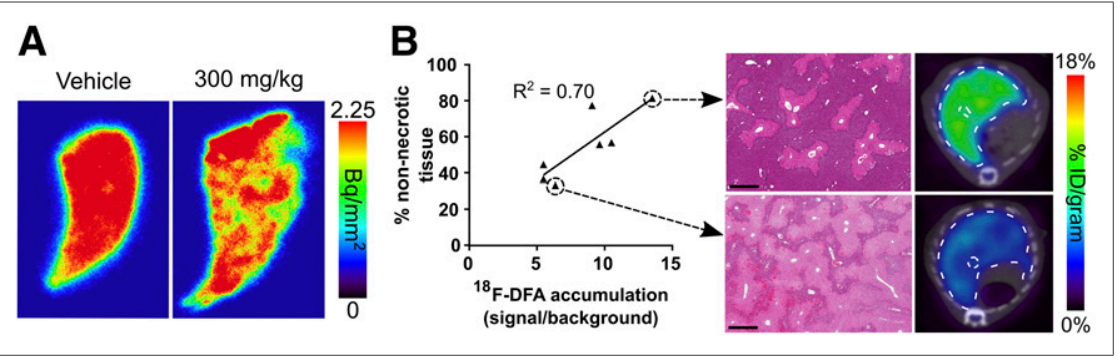

FIGURE 3. ${ }^{18} \mathrm{~F}-\mathrm{DFA}$ accumulation measures functional liver tissue after acetaminophen-induced liver injury. (A) Digital autoradiography of liver sections from mice treated with saline vehicle or $300 \mathrm{mg} / \mathrm{kg}$ acetaminophen for $7 \mathrm{~h}$ and injected with ${ }^{18} \mathrm{~F}-\mathrm{DFA} . n=2$. (B) Correlation between percentage nonnecrotic tissue and hepatic ${ }^{18} \mathrm{~F}$-DFA accumulation in mice treated with $300 \mathrm{mg} / \mathrm{kg}$ acetaminophen for $21 \mathrm{~h}$ (left). Representative H\&E-stained liver sections and transverse ${ }^{18} \mathrm{~F}-\mathrm{DFA}$ PET/CT images (right). Scale bars represent $500 \mu \mathrm{m} . n=7$.

nonnecrotic liver tissue. Digital autoradiography of liver sections of mice treated with $300 \mathrm{mg} / \mathrm{kg}$ acetaminophen and injected with ${ }^{18} \mathrm{~F}$ DFA displayed heterogeneous ${ }^{18} \mathrm{~F}-\mathrm{DFA}$ accumulation compared with liver sections of vehicle-treated mice (Fig. 3A), consistent with the heterogeneous pattern of necrosis present in liver sections of $300 \mathrm{mg} / \mathrm{kg}$ acetaminophen-treated mice (Supplemental Fig. 1D). The percentage of nonnecrotic liver tissue from mice treated with $300 \mathrm{mg} / \mathrm{kg}$ acetaminophen significantly correlated $\left(R^{2}=0.70\right.$; $P$ value for slope being significantly nonzero: 0.018$)$ with hepatic ${ }^{18}$ F-DFA accumulation in the same mice (Fig. 3B). Collectively the data suggest that in this system, hepatic ${ }^{18} \mathrm{~F}-\mathrm{DFA}$ accumulation as measured by PET imaging provides a whole-organ view of functional hepatocyte density in the liver.

\section{PET Imaging with ${ }^{18}$ F-DFA Can Monitor the Efficacy of Treatments for Acetaminophen Overdose}

In other fields, PET imaging has proven effective for monitoring therapeutic responses (33). Approved therapies for acetaminophen overdose are limited but new treatments are in development $(34,35)$. ${ }^{18} \mathrm{~F}$-DFA PET imaging could potentially monitor the efficacy of these treatments and provide data to complement or anticipate changes in blood biochemistry measurements. NAC administration at different time points after acetaminophen treatment provides a useful model in which to determine whether PET imaging with ${ }^{18} \mathrm{~F}-\mathrm{DFA}$ can distinguish mice that have or have not been successfully treated for acetaminophen toxicity. Consistent with published results (36), acetaminophen-induced hepatic necrosis was blocked by NAC treatment 1 but not $4 \mathrm{~h}$ after $300 \mathrm{mg} / \mathrm{kg}$ acetaminophen treatment (Fig. 4A). Mice treated with $300 \mathrm{mg} / \mathrm{kg}$ acetaminophen followed by NAC $1 \mathrm{~h}$ later accumulated ${ }^{18} \mathrm{~F}$-DFA in the liver at levels similar to vehicle-treated mice $(P=0.88)$ and significantly higher than mice treated with NAC $4 \mathrm{~h}$ after $300 \mathrm{mg} / \mathrm{kg}$ acetaminophen treatment $(P=0.009$; Figs. 4B and $4 \mathrm{C}$ ). Hepatic ${ }^{18} \mathrm{~F}-\mathrm{DFA}$ accumulation in mice treated with $300 \mathrm{mg} / \mathrm{kg}$ acetaminophen followed by NAC $4 \mathrm{~h}$ later was indistinguishable from hepatic ${ }^{18} \mathrm{~F}$-DFA accumulation in mice treated only with $300 \mathrm{mg} / \mathrm{kg}$ acetaminophen $(P=0.09$; Figs. $2 \mathrm{~B}$ and $4 \mathrm{C})$. These results suggest that ${ }^{18} \mathrm{~F}-\mathrm{DFA}$ PET imaging can function as a biomarker to monitor therapies to treat acute liver injury.

\section{Ribose Salvage Activity Is Similar Between Mouse and Human \\ Hepatocytes}

${ }^{18} \mathrm{~F}-\mathrm{DFA}$ is not yet approved for use in humans, but isolated human hepatocytes can be analyzed in culture and engrafted into mice. ${ }^{18}$ F-DFA measures ribose salvage activity (15). Isolated mouse and human hepatocytes in culture consume ribose at a similar rate $(P=0.31$; Fig. 5A).

Human hepatocytes administered to FRG mice can engraft into and repopulate the liver of these mice after NTBC withdrawal (29). FRG mice were engrafted with human hepatocytes and imaged with ${ }^{18}$ F-DFA PET. Immunohistochemical staining for the FAH enzyme, which is only present in the engrafted human hepatocytes, in liver sections from these mice suggests that $71 \% \pm 3.6 \%$ of the liver hepatocytes are of human origin (Fig. 5B). Hepatic ${ }^{18}$ F-DFA accumulation in these mice was indistinguishable from hepatic ${ }^{18} \mathrm{~F}-\mathrm{DFA}$ accumulation in nonengrafted control FRG mice maintained on NTBC (e.g., mice in which the livers only contain mouse hepatocytes) $(P=0.06$; Fig. $5 \mathrm{C})$. The behavior of ${ }^{18} \mathrm{~F}-\mathrm{DFA}$ in

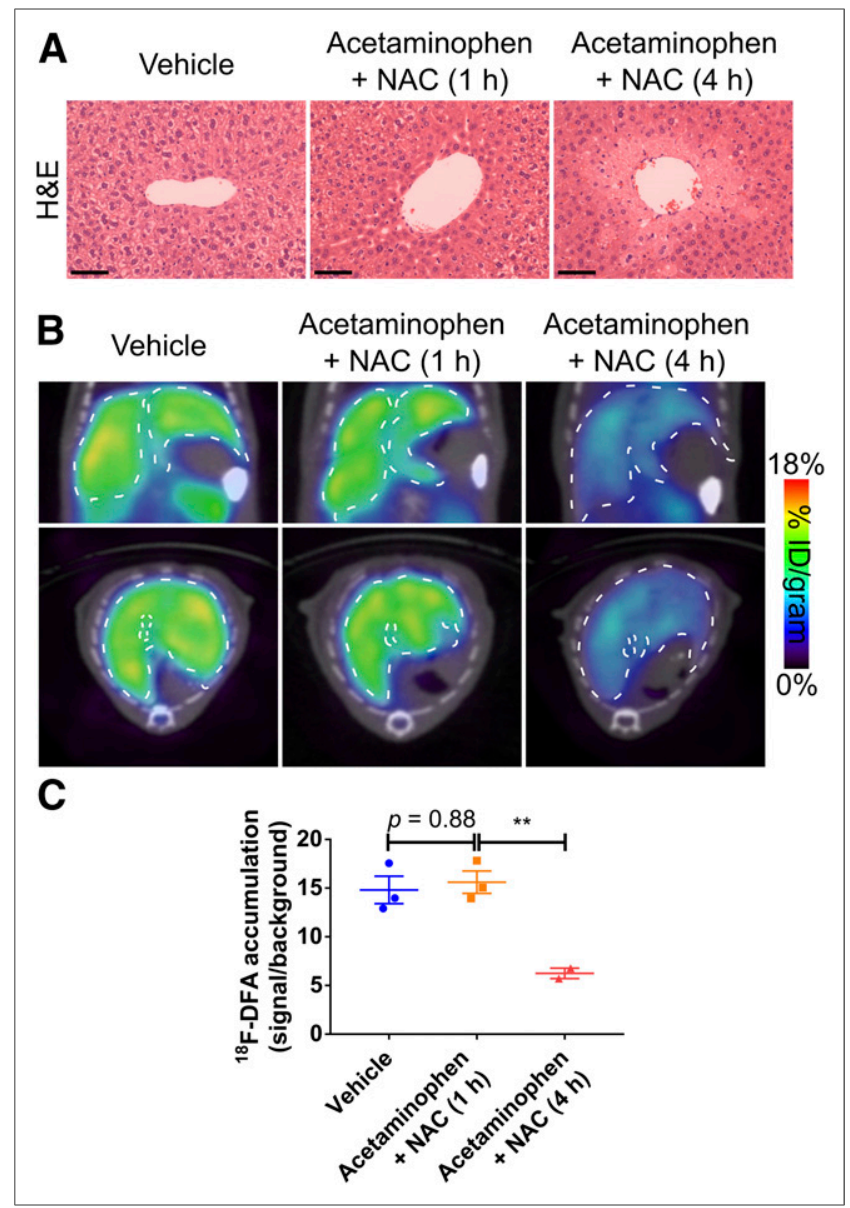

FIGURE 4. PET imaging with ${ }^{18} \mathrm{~F}-\mathrm{DFA}$ can monitor the efficacy of treatments for acetaminophen overdose. Representative H\&E-stained liver sections (A); representative transverse and coronal ${ }^{18} \mathrm{~F}-\mathrm{DFA}$ PET/CT images (B); and quantification of hepatic ${ }^{18} \mathrm{~F}-\mathrm{DFA}$ accumulation in mice treated for $21 \mathrm{~h}$ with saline vehicle, with NAC $1 \mathrm{~h}$ after $300 \mathrm{mg} / \mathrm{kg}$ acetaminophen, or with NAC $4 \mathrm{~h}$ after $300 \mathrm{mg} / \mathrm{kg}$ acetaminophen (C). Scale bars represent $100 \mu \mathrm{m}$. Vehicle: $n=3$; acetaminophen + NAC $(1 \mathrm{~h}): n=3$; acetaminophen + NAC $(4 h): n=2$. One-way ANOVA with Tukey correction. ${ }^{\star \star} P<0.01$. 


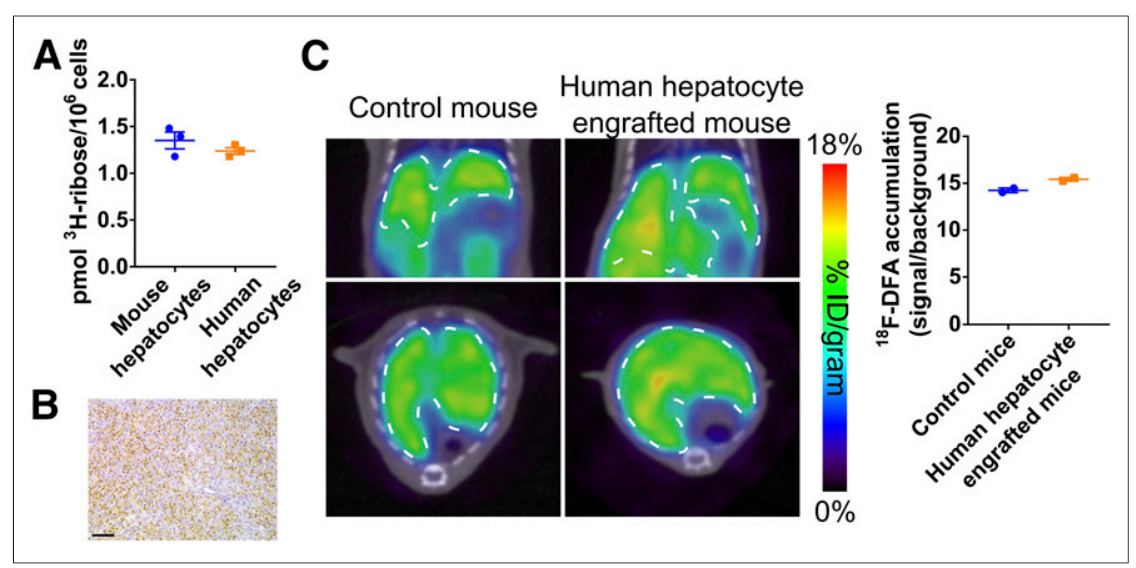

FIGURE 5. Ribose salvage activity is similar between mouse and human hepatocytes. (A) ${ }^{3} \mathrm{H}-$ ribose consumption in mouse and human hepatocytes in cell culture. $n=3$. (B) Representative mouse liver tissue section from mouse treated with human hepatocytes, immunostained for FAH. Scale bar represents $100 \mu \mathrm{m}$. (C) Representative coronal and transverse ${ }^{18} \mathrm{~F}-\mathrm{DFA}$ PET/CT images of control mice and mice for which livers are engrafted with human hepatocytes (left). Quantification of hepatic ${ }^{18} \mathrm{~F}-\mathrm{DFA}$ accumulation in these mice (right). $n=2$.

humans will depend both on hepatic ribose salvage activity and the metabolism of ${ }^{18} \mathrm{~F}$-DFA by other organs and tissues in the body. Nevertheless, these data may suggest that PET imaging with a radiotracer that measures ribose salvage activity could provide information on liver function in humans.

\section{DISCUSSION}

Various approaches have been used to monitor the liver during drug-induced acute liver injury, including liver biopsies and biochemical tests of liver function $(1,6-9,13,14)$. There are several reasons why PET imaging may complement and provide additional information to these assays. Liver biopsies sample 1/50,000 to $1 / 100,000$ of the liver, leading to significant sampling error (3740). This may be especially true when the hepatic disease manifests heterogeneously, such as during acute liver injury $(7,9)$. PET imaging provides a view of the entire liver and eliminates sampling error. Biochemical assessments of liver function from plasma are indirect, diluted across the entire blood volume, and confounded during acute liver failure when various processes are occurring simultaneously (41). PET imaging with ${ }^{18} \mathrm{~F}$-DFA allows for the direct visualization and quantification of a critical parameter: functional hepatocytes. ${ }^{18} \mathrm{~F}$-DFA is not the only radiotracer that accumulates in the liver through specific biochemical processes, and other tracers include ${ }^{99 \mathrm{~m} T c-l a b e l e d}$ galactosyl human serum albumin and $2-{ }^{18}$ F-fluoro-2-deoxygalactose $(42,43)$. Future studies will be required to compare ${ }^{18} \mathrm{~F}$-DFA with these and other tracers in this same model.

Many treatments for acetaminophen-induced hepatotoxicity work by preventing liver damage $(35,44)$. These treatments, exemplified by NAC, can have a profound impact on patient health but their efficacy is limited to very early after acetaminophen ingestion, before hepatocellular damage has occurred (6). Our data suggest that a threshold level of functional hepatocytes are required for survival after high-dose acetaminophen. We identify that hepatic ${ }^{18}$ F-DFA accumulation increases specifically in the surviving mice between 7 and $21 \mathrm{~h}$ after acetaminophen treatment, suggesting a potentially important role for liver regeneration in reaching that threshold. This suggestion is consistent with preclinical studies indicating that stimulating liver regeneration can improve the survival of mice treated with high-dose acetaminophen and limited clinical data suggesting that biomarkers of liver regeneration may be useful for identifying patients who will survive acetaminophen overdose without a liver transplant $(11,45-48)$.

\section{Implications for Human Studies}

We demonstrate that PET imaging with ${ }^{18} \mathrm{~F}-\mathrm{DFA}$ can be used to distinguish mice that will survive acetaminophen overdose from those that will not and, while appreciating important differences between mice and humans, postulate that this approach may have similar utility in humans. ${ }^{18} \mathrm{~F}$ DFA measures ribose salvage activity (15), and we demonstrate that in culture and engrafted into the livers of mice, human hepatocytes have levels of ribose salvage activity similar to those of mouse hepatocytes. However, whether the approach here works in humans will depend on several additional factors. One factor is whether a PET scan can be obtained in sufficient time to affect clinical decision making. The mouse model we use shares many features of the clinical human disease but differs in the speed at which liver failure occurs $(6,49-$ 51). Mice can succumb to high-dose acetaminophen treatment within $24 \mathrm{~h}$ whereas humans often do not present with clear symptoms of acetaminophen overdose for at least $72 \mathrm{~h}$. Symptoms can last for months, although action is often taken within 3-5 $\mathrm{d}$ of presentation $(1,6,49-52)$. Three to $5 \mathrm{~d}$ is a short but not inconceivable time period in which to obtain and analyze a PET scan. Clinical PET protocols have been developed for imaging patients within $24 \mathrm{~h}$ of presentation (53-57). Most liver transplants in America are performed at fewer than 100 sites (58), suggesting that if a rapid protocol were developed, it would need only to be instituted at a limited number of specialized centers.

Another important factor to consider when translating this approach to humans is the patient-to-patient variability in hepatic ${ }^{18} \mathrm{~F}-\mathrm{DFA}$ accumulation. A patient with acetaminophen overdose would likely only be imaged once. High patient-to-patient variability in hepatic ${ }^{18} \mathrm{~F}-\mathrm{DFA}$ accumulation would make it challenging to differentiate between, for example, an individual with naturally low hepatic ${ }^{18} \mathrm{~F}-\mathrm{DFA}$ accumulation from an individual with low hepatic ${ }^{18} \mathrm{~F}$-DFA accumulation due to a dramatic loss of hepatocytes. ${ }^{18} \mathrm{~F}-\mathrm{DFA}$ has not been tested yet in humans, so we cannot report on patient-to-patient variability. However we show that the entropy present in the PET images has the lowest coefficient of variation among the variables analyzed within the cohort of treated mice and may represent an important quantity to evaluate if this approach is tested in humans.

\section{CONCLUSION}

We demonstrate that ${ }^{18} \mathrm{~F}$-DFA PET imaging provides a quantitative, whole-organ measure of the functional hepatocyte density after acetaminophen-induced acute liver injury. As with any liver test, we do not expect that these results by themselves will be absolutely predictive of acute liver failure in humans. We do anticipate that in combination with other measures, including those related to nonhepatic organ failure, the information gained through 
this PET assay may improve the allocation of livers for transplant. Acetaminophen overdose is the most prevalent, though not the only, cause of acute liver failure $(2,6,50,59)$. Other causes of acute liver injury include Hepatitis B, Wilson disease, and idiosyncratic druginduced liver injury caused by such drugs as the epidermal growth factor receptor inhibitor gefitinib, the antiretroviral maraviroc, and the epilepsy medication levetiracetam $(2,3)$. Nothing about the biochemistry of hepatic ${ }^{18} \mathrm{~F}$-DFA accumulation suggests that the results demonstrated here would be specific for acetaminophen-induced acute liver injury. Thus, it will be interesting to test this PET imaging approach in other models of acute and chronic liver injury.

\section{DISCLOSURE}

This work was supported by NIH/NCATS grant \#UL1TR000124 (to Peter M. Clark), CIRM grant \#TR4-06831 (to Gerald S. Lipshutz), NIH/NINDS grant \#1R01NS100979-01 (to Gerald S. Lipshutz), the Parker Institute for Cancer Immunotherapy (PICI) grant \#20163828 (to Owen N. Witte), and the Broad Stem Cell Research Center at UCLA. Peter M. Clark and Owen N. Witte are inventors on a patent, held by the Regents of the University of California, that describes the ${ }^{18}$ F-DFA radiotracer. No other potential conflict of interest relevant to this article was reported.

\section{ACKNOWLEDGMENTS}

We thank members of the Crump Preclinical Imaging Technology Center, the Crump Cyclotron and Radiochemistry Technology Center, and the UCLA Translational Pathology Core Laboratory for their assistance. We thank Ralph and Marjorie Crump for their donation to the UCLA Crump Institute for Molecular Imaging. We thank Dr. Ali Zarrinpar for helpful discussions on acute liver injury in humans. We thank Drs. Claire Faltermeier and John Van Arnam for helpful suggestions on the manuscript.

\section{REFERENCES}

1. Larson AM, Polson J, Fontana RJ, et al. Acetaminophen-induced acute liver failure: results of a United States multicenter, prospective study. Hepatology. 2005;42:1364-1372.

2. Reuben A, Koch DG, Lee WM, Acute Liver Failure Study Group. Drug-induced acute liver failure: results of a U.S. multicenter, prospective study. Hepatology. 2010;52:2065-2076

3. Bunchorntavakul C, Reddy KR. Drug hepatotoxicity: newer agents. Clin Liver Dis. 2017;21:115-134.

4. Robles-Diaz M, Lucena MI, Kaplowitz N, et al. Use of Hy's law and a new composite algorithm to predict acute liver failure in patients with drug-induced liver injury. Gastroenterology. 2014;147:109-118.

5. Björnsson E, Olsson R. Outcome and prognostic markers in severe drug-induced liver disease. Hepatology. 2005;42:481-489.

6. Lancaster EM, Hiatt JR, Zarrinpar A. Acetaminophen hepatotoxicity: an updated review. Arch Toxicol. 2015;89:193-199.

7. Singhal A, Vadlamudi S, Stokes K, et al. Liver histology as predictor of outcome in patients with acute liver failure. Transpl Int. 2012;25:658-662.

8. Scotto J, Opolon P, Etévé J, Vergoz D, Thomas M, Caroli J. Liver biopsy and prognosis in acute liver failure. Gut. 1973;14:927-933.

9. Hanau C, Munoz SJ, Rubin R. Histopathological heterogeneity in fulminant hepatic failure. Hepatology. 1995;21:345-351.

10. Brown AT, Ou X, James LP, et al. Correlation of MRI findings to histology of acetaminophen toxicity in the mouse. Magn Reson Imaging. 2012;30:283-289.

11. Shakil AO, Jones BC, Lee RG, Federle MP, Fung JJ, Rakela J. Prognostic value of abdominal CT scanning and hepatic histopathology in patients with acute liver failure. Dig Dis Sci. 2000;45:334-339.

12. Romero M, Palmer SL, Kahn JA, et al. Imaging appearance in acute liver failure: correlation with clinical and pathology findings. Dig Dis Sci. 2014;59:1987-1995.

13. McPhail MJW, Farne H, Senvar N, Wendon JA, Bernal W. Ability of King's College Criteria and Model for End-Stage Liver Disease Scores to predict mortality of patients with acute liver failure: a meta-analysis. Clin Gastroenterol Hepatol. 2016;14:516-525.e5.

14. Bailey B, Amre DK, Gaudreault P. Fulminant hepatic failure secondary to acetaminophen poisoning: a systematic review and meta-analysis of prognostic criteria determining the need for liver transplantation. Crit Care Med. 2003;31:299-305.

15. Clark PM, Flores G, Evdokimov NM, et al. Positron emission tomography probe demonstrates a striking concentration of ribose salvage in the liver. Proc Natl Acad Sci USA. 2014;111:E2866-E2874.

16. Evdokimov NM, Clark PM, Flores G, et al. Development of 2-deoxy-2-[ $\left.{ }^{18} \mathrm{~F}\right]$ fluororibose for positron emission tomography imaging liver function in vivo. J Med Chem. 2015;58:5538-5547.

17. Collins J, Waldmann CM, Drake C, et al. Production of diverse PET probes with limited resources: $24{ }^{18} \mathrm{~F}$-labeled compounds prepared with a single radiosynthesizer. Proc Natl Acad Sci USA. 2017;114:11309-11314.

18. Sommer C, Straehle C, Köthe U, Hamprecht FA. Ilastik: interactive learning and segmentation toolkit. In: 2011 IEEE International Symposium on Biomedical Imaging: From Nano to Macro. 2011 Institute of Electrical and Electronics Engineers website. https://ieeexplore.ieee.org/document/5872394/. Accessed June 27, 2018.

19. Schneider CA, Rasband WS, Eliceiri KW. NIH Image to ImageJ: 25 years of image analysis. Nat Methods. 2012;9:671-675.

20. Shu CJ, Radu CG, Shelly SM, et al. Quantitative PET reporter gene imaging of CD8 $+\mathrm{T}$ cells specific for a melanoma-expressed self-antigen. Int Immunol. 2009;21:155-165.

21. Hur KY, So J-S, Ruda V, et al. IRE1 $\alpha$ activation protects mice against acetaminophen-induced hepatotoxicity. J Exp Med. 2012;209:307-318.

22. McGill MR, Sharpe MR, Williams CD, Taha M, Curry SC, Jaeschke H. The mechanism underlying acetaminophen-induced hepatotoxicity in humans and mice involves mitochondrial damage and nuclear DNA fragmentation. J Clin Invest. 2012;122:1574-1583.

23. Kheradpezhouh E, Ma L, Morphett A, Barritt GJ, Rychkov GY. TRPM2 channels mediate acetaminophen-induced liver damage. Proc Natl Acad Sci USA. 2014;111:3176-3181.

24. Agarwal S, Holton KL, Lanza R. Efficient differentiation of functional hepatocytes from human embryonic stem cells. Stem Cells. 2008;26:1117-1127.

25. Zhang J, Song S, Pang Q, et al. Serotonin deficiency exacerbates acetaminopheninduced liver toxicity in mice. Sci Rep. 2015;5:8098.

26. Phelps ME. Positron emission tomography provides molecular imaging of biological processes. Proc Natl Acad Sci USA. 2000;97:9226-9233.

27. Gambhir SS. Molecular imaging of cancer with positron emission tomography. Nat Rev Cancer. 2002;2:683-693.

28. Iozzo P, Geisler F, Oikonen V, et al. Insulin stimulates liver glucose uptake in humans: an ${ }^{18}$ F-FDG PET Study. J Nucl Med. 2003;44:682-689.

29. Azuma H, Paulk N, Ranade A, et al. Robust expansion of human hepatocytes in Fah-/-/Rag2-/-/Il2rg-/- mice. Nat Biotechnol. 2007;25:903-910.

30. Tixier F, Le Rest CC, Hatt M, et al. Intratumor heterogeneity characterized by textural features on baseline ${ }^{18} \mathrm{~F}$-FDG PET images predicts response to concomitant radiochemotherapy in esophageal cancer. J Nucl Med. 2011;52:369_ 378.

31. Cook GJR, Yip C, Siddique M, et al. Are pretreatment ${ }^{18}$ F-FDG PET tumor textural features in non-small cell lung cancer associated with response and survival after chemoradiotherapy? J Nucl Med. 2013;54:19-26.

32. Cook GJR, Siddique M, Taylor BP, Yip C, Chicklore S, Goh V. Radiomics in PET: principles and applications. Clin Transl Imaging. 2014;2:269-276.

33. Clark PM, Ebiana VA, Gosa L, Cloughesy TF, Nathanson DA. Harnessing preclinical molecular imaging to inform advances in personalized cancer medicine. J Nucl Med. 2017;58:689-696.

34. Soeda J, Mouralidarane A, Ray S, et al. The $\beta$-adrenoceptor agonist isoproterenol rescues acetaminophen-injured livers through increasing progenitor numbers by Wnt in mice. Hepatology. 2014;60:1023-1034.

35. Ni H-M, Bockus A, Boggess N, Jaeschke H, Ding W-X. Activation of autophagy protects against acetaminophen-induced hepatotoxicity. Hepatology. 2012;55:222-232.

36. James LP, McCullough SS, Lamps LW, Hinson JA. Effect of N-acetylcysteine on acetaminophen toxicity in mice: relationship to reactive nitrogen and cytokine formation. Toxicol Sci. 2003;75:458-467.

37. Nord HJ. Biopsy diagnosis of cirrhosis: blind percutaneous versus guided direct vision techniques: a review. Gastrointest Endosc. 1982;28:102-104.

38. Jeffers LJ, Cortes RA, Bejarano PA, et al. Prospective evaluation of FIBROSpect II for fibrosis detection in hepatitis $\mathrm{c}$ and $\mathrm{b}$ patients undergoing laparoscopic biopsy. Gastroenterol Hepatol (N Y). 2007;3:367-376.

39. Soloway RD, Baggenstoss AH, Schoenfield LJ, Summerskill WH. Observer error and sampling variability tested in evaluation of hepatitis and cirrhosis by liver biopsy. Am J Dig Dis. 1971;16:1082-1086. 
40. Abdi W, Millan JC, Mezey E. Sampling variability on percutaneous liver biopsy. Arch Intern Med. 1979;139:667-669.

41. John Dubray B, Zarrinpar A. Quantification of hepatic functional capacity: a call for standardization. Expert Rev Gastroenterol Hepatol. 2016;10:9-11.

42. Vera DR, Krohn KA, Stadalnik RC, Scheibe PO. Tc- ${ }^{99} \mathrm{~m}$-galactosyl-neoglycoalbumin: in vivo characterization of receptor-mediated binding to hepatocytes. Radiology. 1984;151:191-196.

43. Sørensen M, Frisch K, Bender D, Keiding S. The potential use of 2-[18F]fluoro2-deoxy-D-galactose as a PET/CT tracer for detection of hepatocellular carcinoma. Eur J Nucl Med Mol Imaging. 2011;38:1723-1731.

44. Lauterburg BH, Corcoran GB, Mitchell JR. Mechanism of action of $N$-acetylcysteine in the protection against the hepatotoxicity of acetaminophen in rats in vivo. J Clin Invest. 1983;71:980-991.

45. Schmidt LE, Dalhoff K. Alpha-fetoprotein is a predictor of outcome in acetaminophen-induced liver injury. Hepatology. 2005;41:26-31.

46. Horn KD, Wax P, Schneider SM, et al. Biomarkers of liver regeneration allow early prediction of hepatic recovery after acute necrosis. Am J Clin Pathol. 1999; 112:351-357.

47. Hu B, Colletti LM. Stem cell factor and c-kit are involved in hepatic recovery after acetaminophen-induced liver injury in mice. Am J Physiol Gastrointest Liver Physiol. 2008;295:G45-G53.

48. Donahower BC, McCullough SS, Hennings L, et al. Human recombinant vascular endothelial growth factor reduces necrosis and enhances hepatocyte regeneration in a mouse model of acetaminophen toxicity. J Pharmacol Exp Ther. 2010;334:33-43.

49. Clark R, Borirakchanyavat V, Davidson AR, et al. Hepatic damage and death from overdose of paracetamol. Lancet. 1973;1:66-70.
50. Yoon E, Babar A, Choudhary M, Kutner M, Pyrsopoulos N. Acetaminophen-induced hepatotoxicity: a comprehensive update. J Clin Transl Hepatol. 2016;4:131-142.

51. Ostapowicz G, Fontana RJ, Schiødt FV, et al. Results of a prospective study of acute liver failure at 17 tertiary care centers in the United States. Ann Intern Med. 2002;137:947-954.

52. O'Grady JG, Wendon J, Tan KC, et al. Liver transplantation after paracetamol overdose. BMJ. 1991;303:221-223.

53. Markus R, Reutens DC, Kazui S, et al. Topography and temporal evolution of hypoxic viable tissue identified by ${ }^{18} \mathrm{~F}$-fluoromisonidazole positron emission tomography in humans after ischemic stroke. Stroke. 2003;34:2646-2652.

54. Read SJ, Hirano T, Abbott DF, et al. Identifying hypoxic tissue after acute ischemic stroke using PET and ${ }^{18}$ F-fluoromisonidazole. Neurology. 1998;51:1617-1621.

55. Markus R, Reutens DC, Kazui S, et al. Hypoxic tissue in ischaemic stroke: persistence and clinical consequences of spontaneous survival. Brain. 2004;127: 1427-1436.

56. Lee G-H, Kim JS, Oh SJ, Kang D-W, Kim JS, Kwon SU. ${ }^{18}$ F-fluoromisonidazole (FMISO) positron emission tomography (PET) predicts early infarct growth in patients with acute ischemic stroke. J Neuroimaging. 2015;25:652-655.

57. Heiss WD, Kracht L, Grond M, et al. Early $\left[{ }^{11} \mathrm{C}\right]$ flumazenil/ $\mathrm{H}_{2} \mathrm{O}$ positron emission tomography predicts irreversible ischemic cortical damage in stroke patients receiving acute thrombolytic therapy. Stroke. 2000;31:366-369.

58. Brown RS, Russo MW, Lai M, et al. A survey of liver transplantation from living adult donors in the United States. N Engl J Med. 2003;348:818-825.

59. Nourjah P, Ahmad SR, Karwoski C, Willy M. Estimates of acetaminophen (Paracetomal)-associated overdoses in the United States. Pharmacoepidemiol Drug Saf. 2006;15:398-405. 